\title{
Hubungan Antara Dukungan Keluarga Dengan Perilaku Perawatan Hipertensi Yang Dilakukan Oleh Keluarga Di Rumah
}

\author{
Elly Daziah ${ }^{1}$, Sri Rahayu ${ }^{2 *}$ \\ ${ }^{1}$ Mahasiswa Sekolah Tinggi Ilmu Kesehatan Jayakarta, Jakarta \\ ${ }^{2}$ Dosen Program Studi Ilmu Keperawatan Sekolah Tinggi Ilmu Kesehatan Jayakarta, Jakarta \\ Jalan Raya PKP, Kel. Kelapa Dua Wetan, Kel. Ciracas, Kec. Jakarta Timur, Kode Pos: 13730 \\ *correspondence author: Handphone: 082136416441, E-mail: srirahayu1903@gmail.com
}

DOI: $10.33859 / \mathrm{dksm} . v 11 \mathrm{i} 1.477$

Abstrak
Latar Belakang: Angka prevalensi hipertensi akan terus meningkat secara global dan diprediksikan
pada tahun 2025 sebanyak 29\% orang dewasa di seluruh dunia akan mengalami hipertensi. Hipertensi
yang tidak mendapatkan penanganan yang baik akan menyebabkan komplikasi yang merupakan
penyebab kematian nomor 5 pada semua kelompok umur. Agar terhindar dari komplikasi maka
dibutuhkan dukungan keluarga untuk melakukan perawatan hipertensi.
Tujuan: Untuk mengetahui hubungan dukungan keluarga dengan perilaku perawatan hipertensi yang
dilakukan oleh keluarga di rumah.
Metode Penelitian: Desain penelitian korelasional dengan pendekatan cross-sectional digunakan
dalam penelitian ini. Sampel yang bersedia menjadi responden sejumlah 35 responden dengan teknik
simple random sampling. Uji Chi-Square digunakan untuk menganalisa data.
Hasil: Ada hubungan yang signifikan antara dukungan keluarga dengan perilaku perawatan
hipertensi yang dilakukan oleh keluarga di rumah dengan nilai $p$-value = 0,003. Sedangkan bentuk
dukungan keluarga yang berhubungan dengan perilaku perawatan hipertensi yang dilakukan oleh
keluarga di rumah adalah dukungan instrumental ( $p$-value = 0,001), dukungan informasi $(p$-value $=$
0,000) dan dukungan emosional ( $p$-value =0,004). Jadi dapat disimpulkan bahwa dukungan keluarga
perlu diperhatikan dalam melakukan perawatan hipertensi di rumah.
Kata kunci: dukungan keluarga, hipertensi, perilaku perawatan




\title{
The Relationship Between Family Support And Caring Behavior of Hypertension by Families at Home
}

\begin{abstract}
Background: Hypertension prevalence rates will continue to increase globally and it is predicted in 2025 as many as 29\% of adults worldwide will experience to have hypertension. Hypertension with inadequate treatment will cause complications which is the number fifth cause of death in all ages. In order to avoid complications, family support was required to treat hypertension.

Objective: To determine the relationship between family support and caring behavior of hypertension by families at home,

Methods: Correlational research design with cross sectional approach was used. A sample of 35 respondents willing to join by simple random sampling. Chi-Square Test was used to analyze the data.

Results: There was a significant relationship between family support and caring behavior of hypertension by families at home with value p-value $=0,003$. While the domain of family support which related to caring behavior of hypertension by families at home are instrumental support ( $p$-value $=0,001)$, informational support ( $p$-value $=0,000)$ and emotional support ( $p$-value $=0,004)$. Finally, it can be concluded family support need to be considered in treating hypertension at home.
\end{abstract}

Keywords: caring behavior, family support, hypertension

\section{Pendahuluan}

Data World Health Organization (WHO) menyatakan bahwa hipertensi adalah salah satu kontributor utama penyakit jantung dan stroke yang merupakan penyebab kematian dan kecacatan nomor satu di dunia (WHO, 2012). WHO juga menyatakan bahwa pasien hipertensi terbanyak ada di negara berkembang. Data Riset Kesehatan Dasar (Riskesdas) (2013) menunjukkan bahwa hipertensi di Indonesia memiliki prevalensi tertinggi sebesar $25,8 \%$ dibandingkan dengan penyakit yang lain (kanker, diabetes melitus, penyakit jantung koroner, gagal jantung, stroke, dan gagal ginjal). Jika dilihat dari seluruh provinsi di Indonesia, Jawa Barat termasuk Kecamatan Bekasi Timur menempati urutan terbanyak ke-4 untuk prevalensi hipertensi. Hasil Survei Indikator Kesehatan Nasional tahun 2016 menunjukkan bahwa prevalensi hipertensi meningkat menjadi 32,4\% (Kemenkes RI, 2017). Angka prevalensi hipertensi akan terus meningkat secara global dan diprediksikan pada tahun 2025 sebanyak $29 \%$ orang dewasa di seluruh dunia akan mengalami hipertensi (Kemenkes RI, 2017).

Hipertensi yang tidak mendapatkan penanganan yang baik akan menyebabkan komplikasi penyakit lain. Data WHO (2012) 
menyebutkan bahwa hipertensi merupakan kondisi berisiko tinggi yang menyebabkan kematian akibat stroke (51\%) dan jantung koroner (45\%). Hal ini menjadi sangat penting untuk diperhatikan agar komplikasi hipertensi dapat dicegah dan kualitas kesehatan pasien hipertensi dapat di tingkatkan.

Kualitas kesehatan pasien hipertensi tersebut dapat ditingkatkan dengan cara memodifikasi gaya hidup yaitu dengan membatasi asupan garam, menurunkan berat badan, menghindari minuman berkafein, berhenti merokok dan menghindari minuman beralkohol (Kemenkes RI, 2014). Olahraga juga dianjurkan bagi pasien hipertensi. Istirahat (6-8 jam) dan mengendalikan stress juga penting untuk pasien hipertensi (Kemenkes RI, 2014). Selain itu mengajak keluarga untuk ikut berperan serta dalam program perawatan atau pengobatan hipertensi merupakan support sistem yang penting bagi pasien hipertensi.

Dukungan keluarga merupakan faktor penting dalam proses pengobatan dan pencegahan penyakit hipertensi. Keluarga memiliki peranan penting dalam pengawasan dan pencegahan terjadinya komplikasi hipertensi serta dapat memberikan dukungan dan membuat keputusan mengenai perawatan yang dilakukan oleh pasien hipertensi (Tumenggung, 2013). Selain itu juga dukungan keluarga merupakan unsur penting dalam keberhasilan untuk mempertahankan dan menjaga kesehatan setiap individu anggota keluarga (Friedman, Marilyn, M., Bowden, V. R., \& Jones, 2010). Sehingga hubungan antara pasien dan keluarga sangatlah kuat.

Hasil penelitian sebelumnya menjelaskan adanya hubungan antara dukungan keluarga dengan kepatuhan diet hipertensi, perilaku pengendalian hipertensi, dan perilaku perawatan hipertensi (Dewi, K. C. C., Prapti, N. K. G., \& Saputra, 2016; Herlinah, L., Wiarsih, W., \& Rekawati, 2013; Susriyanti, 2014). Pasien hipertensi yang mendapat dukungan keluarga yang tinggi, akan meningkatkan perilaku perawatan hipertensi (Susriyanti, 2014). Akan tetapi, hal ini memerlukan penelitian lebih lanjut untuk memastikan bentuk dukungan keluarga yang berhubungan dengan persepsi pasien tentang perilaku perawatan hipertensi oleh keluarga di rumah pada populasi yang berbeda.

Hasil studi pendahuluan menunjukkan bahwa jumlah pasien hipertensi pada bulan Januari 2018 sebanyak 245 pasien hipertensi yang berobat ke Puskesmas Karang Kitri, Kelurahan Margahayu, Kecamatan Bekasi Timur. Hasil wawancara dengan 10 pasien hipertensi pada tanggal 4 Februari 2018 di wilayah RW 03 Kelurahan Margahayu Kecamatan Bekasi Timur bahwa pasien hipertensi mengatakan jarang memeriksa kesehatannya. Pasien melakukan pemeriksaan kesehatan pada saat kondisi menurun saja. Pasien tidak dilarang oleh keluarganya untuk makan atau minum yang pasien sukai. Pasien juga tidak pernah berolahraga dikarenakan 
keluarganya tidak pernah memberikan support untuk berolahraga serta tidak menemani saat berolahraga. Padahal pasien mengatakan tinggal bersama keluarganya. Maka dari itu, tujuan penelitian ini adalah untuk mengidentifikasi hubungan antara dukungan keluarga dengan perilaku perawatan hipertensi yang dilakukan oleh keluarga di rumah.

\section{Bahan dan Metode}

Penelitian ini merupakan penelitian kuantitatif dengan metode deskriptif korelasional. Desain penelitian yang digunakan adalah dengan rancangan crosssectional. Variabel independen dalam penelitian ini adalah dukungan keluarga, sedangkan variabel dependen adalah perilaku perawatan hipertensi yang dilakukan oleh keluarga di rumah. Penelitian ini dilakukan di wilayah RW 03 Kelurahan Margahayu Kecamatan Bekasi Timur, yaitu pada bulan Maret-Juli tahun 2018. Teknik pengambilan sampel yang digunakan adalah dengan menggunakan teknik simple random sampling. Jumlah sampel yang bersedia menjadi responden sebanyak 35 orang dengan kriteria inklusi dan eklusi.

Kriteria inklusinya adalah warga RW 03 Kelurahan Margahayu Kecamatan Bekasi Timur yang memiliki penyakit hipertensi, memiliki tekanan darah $>140 / 90 \mathrm{mmHg}$, tinggal bersama dengan keluarga, berjenis perempuan atau laki-laki, mampu untuk membaca dan atau menulis, dan bersedia untuk menjadi responden. Sedangkan kriteria eklusinya adalah warga RW 03 Kelurahan Margahayu Kecamatan Bekasi Timur yang mengalami gangguan jiwa, mengalami masalah pendengaran dan penglihatan, dan tinggal sendiri.

Hasil pengujian validitas dari 25 responden indikator variabel dukungan keluarga dinyatakan valid karena nilai $r$ hitung lebih besar dari $r$ tabel. Sedangkan hasil reliabilitas menunjukkan bahwa pernyataan variabel dukungan keluarga dengan cronbach's alpha 0,96 dan pernyataan variable persepsi pasien tentang perilaku perawatan hipertensi oleh keluarga di rumah dengan cronbach's alpha 0,97. Maka kedua kuesioner tersebut dinyatakan sangat reliabel. Untuk masing-masing pernyataan bentuk dukungan keluarga yang berupa dukungan penghargaan dinyatakan cukup reliabel dengan cronbach's alpha 0,53 , dukungan instrumental dinyatakan reliabel dengan cronbach's alpha 0,71, dukungan informasi dan dukungan emosional dinyatakan sangat reliabel dengan cronbach's alpha 0,96 dan 0,87 .

\section{Hasil Penelitian}

\section{a. Karakteristik Pasien}

Karakteristik pasien dalam penelitian ini meliputi usia, jenis kelamin, tingkat pendidikan, pekerjaan, lama sakit, dan hubungan dengan pasien. 
Tabel 1. Distribusi Karakteristik Pasien $(\mathrm{n}=35)$

\begin{tabular}{|c|c|c|c|}
\hline Variabel & Karakteristik & $\mathbf{n}$ & $\%$ \\
\hline \multirow[t]{4}{*}{ Usia } & $36-45$ tahun & 6 & 17,1 \\
\hline & 46-55 tahun & 11 & 31,4 \\
\hline & 56-65 tahun & 12 & 34,3 \\
\hline & $>65$ tahun & 6 & 17,1 \\
\hline \multirow[t]{2}{*}{ Jenis Kelamin } & Laki-laki & 10 & 28,6 \\
\hline & Perempuan & 25 & 71,4 \\
\hline \multirow{5}{*}{$\begin{array}{l}\text { Tingkat } \\
\text { Pendidikan }\end{array}$} & SD & 16 & 45,7 \\
\hline & & & \\
\hline & SMP & 11 & 31,4 \\
\hline & SMA & 4 & 11,4 \\
\hline & D3/S1 & 4 & 11,4 \\
\hline \multirow[t]{2}{*}{ Pekerjaan } & Bekerja & 12 & 34,3 \\
\hline & Tidak bekerja & 23 & 65,7 \\
\hline \multirow[t]{3}{*}{ Lama Sakit } & $<1$ tahun & 4 & 11,4 \\
\hline & $1-5$ tahun & 22 & 62,9 \\
\hline & $>5$ tahun & 9 & 25,7 \\
\hline \multirow{2}{*}{$\begin{array}{l}\text { Hubungan } \\
\text { dengan pasien }\end{array}$} & Pasangan & 19 & 54,3 \\
\hline & Anak & 16 & 45,7 \\
\hline
\end{tabular}

Pada tabel 1 menunjukkan bahwa sebagian besar pasien hipertensi berusia 56-65 tahun sebanyak 12 orang $(34,3 \%)$, berjenis kelamin perempuan sebanyak 25 orang (71,4\%), memiliki tingkat pendidikan SD sebanyak 16 orang $(45,7 \%)$, tidak bekerja sebanyak 23 orang $(65,7 \%)$, lama sakit $1-5$ tahun sebanyak 22 orang $(62,9 \%)$, dan memiliki hubungan dengan pasien sebagai pasangan sebanyak 19 orang $(54,3 \%)$.

\section{b. Hubungan Dukungan Keluarga Dengan Perilaku Perawatan Hipertensi Yang Dilakukan Oleh Keluarga di Rumah}

Pada tabel 2 menunjukkan bahwa dari hasil analisis statistik diperoleh p-value = 0,003 lebih kecil dari $\alpha(0,05)$, maka dapat disimpulkan bahwa ada hubungan yang signifikan antara hubungan dukungan keluarga dengan perilaku perawatan hipertensi yang dilakukan oleh keluarga di rumah. Tabel 2 juga menunjukkan bahwa dari 35 pasien hipertensi, sebanyak 5 orang $(83,3 \%)$ mendapatkan dukungan keluarga rendah dengan perilaku perawatan hipertensi yang dilakukan oleh keluarga di rumah dalam kategori kurang. Sebanyak 5 orang $(55,6 \%)$ mendapatkan dukungan keluarga tinggi dengan perilaku perawatan hipertensi yang dilakukan oleh keluarga di rumah dalam kategori baik.

Selain itu jika melihat hubungan dari setiap bentuk dukungan keluarga, didapatkan data bahwa ada hubungan yang signifikan antara dukungan instrumental dengan perilaku perawatan hipertensi yang dilakukan oleh keluarga di rumah $(p$-value $=0,001)$; ada hubungan yang signifikan antara dukungan informasi dengan perilaku perawatan hipertensi yang dilakukan oleh keluarga di rumah $\quad(p$-value $=0,000)$; ada hubungan yang signifikan antara dukungan emosional dengan perilaku perawatan hipertensi yang dilakukan oleh keluarga di rumah ( $p$-value $=$ 0,004). Sedangkan untuk dukungan penghargaan tidak ada hubungan dengan perilaku perawatan hipertensi yang dilakukan oleh keluarga di rumah( $p$-value $>0,05)$. 
Dinamika Kesehatan Jurnal Kebidanan dan Keperawatan Vol 11 No. 1 Juli 2020 ( ISSN: 2086-3454 EISSN: 2549-4058)

url: http://ojs.dinamikakesehatan.unism.ac.id DOI : https://doi.org/10.33859/dksm.v11i1

Hubungan Antara Dukungan Keluarga Dengan Perilaku Perawatan Hipertensi Yang Dilakukan Oleh Keluarga Di Rumah

Tabel 2. Hubungan Dukungan Keluarga dengan Perilaku Perawatan Hipertensi Yang Dilakukan oleh

Keluarga di Rumah $(\mathrm{n}=35)$

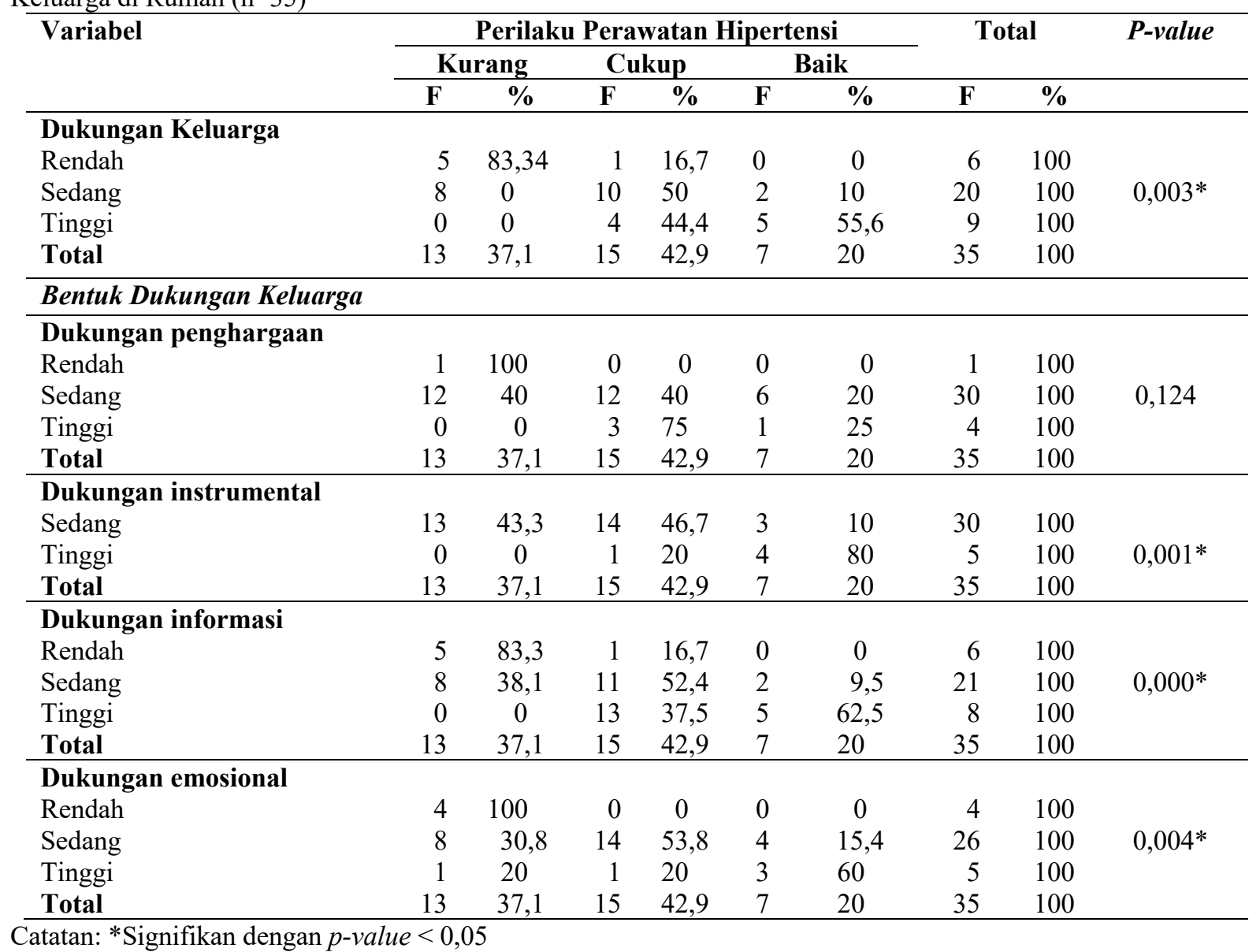

\section{Pembahasan}

\section{a. Karakteristik Pasien}

Sebagian besar pasien hipertensi pada penelitian ini berusia 56-65 tahun. Hasil penelitian ini sejalan dengan hasil penelitian lain dimana usia pasien pada rentang 55-61 tahun (Adriani, 2018). Usia ini masuk dalam kategori masa lansia akhir (Depkes RI, 2009). Umur $>40$ tahun memiliki resiko terkena hipertensi sebesar 11,71 kali dibandingkan dengan umur $<40$ tahun (Anggara, F. H., \& Prayitno, 2013). Semakin bertambahnya usia mengakibatkan tekanan darah meningkat, karena dinding arteri pada usia lanjut akan mengalami penebalan yang mengakibatkan penumpukan zat kolagen pada lapisan otot, sehingga pembuluh darah akan berangsurangsur menyempit dan menjadi kaku (Anggraini, A. D., Waren, A., Situmorang, E., Asputra, H., \& Siahaan, 2009).

Hasil penelitian menunjukkan bahwa perempuan memiliki resiko hipertensi setelah berusia diatas 45 tahun karena efek dari menopouse (Sigalingging, 2011). Hal ini terjadi karena sebelum masa menopuse tubuh perempuan dilindungi oleh hormon estrogen yang berperan dalam meningkatkan kadar High Density Lipoprotein (HDL). Jika Kadar HDL rendah dan LDL (Low Density Lipoprotein) tinggi, maka akan 
mempengaruhi terjadinya proses aterosklerosis yang berujung pada penyempitan pembuluh darah, dan pada akhirnya terjadilah hipertensi (Anggraini, A. D., Waren, A., Situmorang, E., Asputra, H., \& Siahaan, 2009). Hal ini diperkuat dalam bahwa perempuan beresiko terkena hipertensi (Trianni, 2013; Wahyuni., dan Eksanoto, 2013). Untuk jenis kelamin tidak ada hubungannya dengan perilaku perawatan hipertensi (Herlinah, L., Wiarsih, W., \& Rekawati, 2013).

Hasil penelitian ini mayoritas pasien hipertensi berpendidikan SD. Hal ini juga disebutkan dalam penelitian lain (Adriani, 2018; Trianni, 2013). Pasien yang berpendidikan tinggi akan mudah menyerap informasi dan akan memiliki pengetahuan yang lebih baik dari pada pasien dengan tingkat pendidikan yang rendah (Agrina, A., Rini, S. S., \& Hairitama, 2011). Menurut Notoatmodjo (2003) menyatakan bahwa sebagian besar pengetahuan dipengaruhi oleh pengalaman yang didapat dari diri sendiri maupun orang lain, pengalaman dapat diperoleh dari lamanya pasien mengalami suatu penyakit. Secara logika angka kejadian hipertensi cenderung terjadi pada orang dengan pendidikan rendah karena ketidaktahuan tentang gaya hidup sehat. Menurut Sugiharto (2007) menyatakan bahwa tingkat pendidikan dapat mempengaruhi kemampuan dan pengetahuan seseorang dalam menerapkan perilaku hidup sehat, terutama dalam perilaku perawatan hipertensi. Semakin tinggi tingkat pendidikan maka semakin tinggi pula kemampuan seseorang dalam menjaga pola hidupnya agar tetap sehat.

Sebagian besar pasien dalam penelitian ini tidak bekerja yaitu sebesar $65,7 \%$. Hasil penelitian ini sesuai dengan penelitian Siringoringo, M., Hiswani (2013) bahwa 60,54\% pasien juga tidak bekerja. Menurut penelitian Anggara dan Prayitno (2013) menyatakan bahwa orang yang tidak bekerja lebih beresiko menderita hipertensi dari pada yang bekerja karena bekerja akan meningkatkan aktivitas fisik sehingga menurunkan resiko hipertensi.

\section{b. Hubungan dukungan keluarga dengan perilaku perawatan hipertensi yang dilakukan oleh keluarga di rumah}

Teori tentang dukungan keluarga menjelaskan bahwa sikap, tindakan, dan penentuan keluarga terhadap pasien yang sakit (Friedman, Marilyn, M., Bowden, V. R., \& Jones, 2010). Dukungan keluarga sangat diperlukan oleh seorang pasien, karena seseorang yang sedang sakit tentunya membutuhkan perhatian dari keluarga. Perhatian dari keluarga tersebut dapat berupa kasih sayang, perhatian, maupun dukungan terhadap perilaku perawatan hipertensi yang dilakukan oleh keluarga di rumah. Keluarga dengan dukungan yang baik akan menghasilkan perilaku perawatan hipertensi yang baik juga. Sedangkan keluarga dengan dukungan keluarga yang rendah, mereka sibuk 
dengan urusannya sendiri sehingga kurang memperhatikan terhadap keluarga yang sedang sakit.

Hasil penelitian ini membuktikan bahwa ada hubungan yang signifikan antara dukungan keluarga dengan perilaku perawatan hipertensi yang dilakukan oleh keluarga di rumah. Hasil penelitian ini sesuai dengan hasil penelitian Susriyanti (2014)yang menunjukkan bahwa ada hubungan yang signifikan antara dukungan keluarga dengan perilaku perawatan hipertensi. Hasil penelitian lain yang mendukung yaitu penelitian (Herlinah, L., Wiarsih, W., \& Rekawati, 2013) yang menunjukkan ada hubungan antara dukungan keluarga dengan perilaku lansia terhadap pengendalian hipertensi. Ini merefleksikan bahwa dukungan keluarga sangat bermanfaat bagi pasien dalam manajemen perawatan hipertensi.

Menurut Maryam (2008) menjelaskan bahwa keluarga merupakan support system utama bagi keluarganya dalam mempertahankan kesehatannya. Peranan keluarga dalam perawatan keluarga antara lain menjaga atau merawat keluarga, mempertahankan dan meningkatkan status mental serta memberikan motivasi dan memfasilitasi kebutuhan spiritual. Dukungan keluarga merupakan suatu bentuk bantuan yang bertujuan untuk merawat seseorang anggota keluarga dirumah yang mengalami ketidakmampuan atau keterbatasan. Menurut Efendi (2009) mengatakan bahwa keluarga terdiri dari anggota yang saling ketergantungan satu sama lainnya dan berpengaruh dengan yang lainnya. Keluarga bisa menjadi motivator kuat bagi pasien hipertensi apabila keluarga selalu meluangkan waktunya serta menyediakan diri untuk mendampingi dan mengantarkan pasien hipertensi ke pelayanan kesehatan untuk melakukan pemeriksaan tekanan darah. Maka dapat disimpulkan bahwa semakin tinggi dukungan keluarga terhadap pasien maka akan semakin tinggi pula pasien mendapatkan perilaku perawatan hipertensi yang dilakukan oleh keluarga di rumah.

\section{Kesimpulan}

Pada penelitian dapat disimpulkan sebagai berikut:

1. Karakteristik pasien hipertensi tergolong dalam usia lansia akhir, berjenis kelamin perempuan, berpendidikan SD, tidak bekerja, mengalami penyakit hipertensi selama 1-5, dan memiliki hubungan dengan pasien sebagai pasangan.

2. Ada hubungan yang signifikan antara dukungan keluarga dengan perilaku perawatan hipertensi yang dilakukan oleh keluarga di rumah.

\section{Ucapan Terima Kasih}

Segala proses mulai dari penyusunan proposal penelitian, pelaksanaan penelitian, hasil penelitian, pembahasan sampai dengan penulisan manuskrip publikasi ini tidak 
terlepas dari bantuan dan dukungan berbagai pihak. Pada kesempatan ini peneliti hendak mengucapkan terima kasih kepada semua pihak yang telah membantu yaitu dosen pembimbing, para penguji, koordinator skripsi, teman-teman seperjuangan prodi sarjanan keperawatan STIKes Jayakarta, dan juga kedua orangtua yang sangat saya sayangi dan cintai, serta kepada seluruh pihak yang tidak bisa disebutkan namanya satu persatu yang telah membantu dalam menyelesaikan penelitian ini.

\section{Daftar Pustaka}

Adriani, S. W. (2018). Perilaku keluarga dalam mendukung manajemen hipertensi di Kabupaten Jember. The Indonesian Journal of Health Science, 10(2), 36-50.

Agrina, A., Rini, S. S., \& Hairitama, R. (2011). Kepatuhan lansia penderita hipertensi dalam pemenuhan diet hipertensi. Sorot, $6(1), 46-55$.

Anggara, F. H., \& Prayitno, N. (2013). FaktorFaktor yang berhubungan dengan tekanan darah di Puskesmas Telaga Murni, Cikarang Barat tahun 2012. Jurnal Ilmiah Kesehatan, 5(1), 20-25.

Anggraini, A. D., Waren, A., Situmorang, E., Asputra, H., \& Siahaan, S. S. (2009). Faktor-faktor yang berhubungan dengan kejadian hipertensi pada pasien yang berobat di poliklinik dewasa puskesmas Bangkinang periode Januari sampai Juni 2008. Fakultas Kesehatan. Universitas Riau. Files of DrsMed-FK UNRI, 1, 41.

Depkes RI. (2009). Sistem kesehatan nasional, Jakarta.
Dewi, K. C. C., Prapti, N. K. G., \& Saputra, I. K. (2016). Hubungan dukungan keluarga dengan tingkat kepatuhan penatalaksanaan diet lansia dengan hipertensi di lingkungan Kelurahan Tonja. COPING (Community of Publishing in Nursing), 4(1).

Friedman, Marilyn, M., Bowden, V. R., \& Jones, E. G. (2010). Buku Ajar Keperawatan Keluarga : Riset, Teori dan Praktek. Jakarta: EGC.

Herlinah, L., Wiarsih, W., \& Rekawati, E. (2013). Hubungan dukungan keluarga dengan perilaku lansia dalam pengendalian hipertensi, 1(2).

Kemenkes RI. (2014). Infodatin: Pusat data dan informasi kementerian kesehatan RI hipertensi. Retrieved from http://www.depkes.go.id/download.php? file $=$ download/pusdatin/infodatin/infodat in-hipertensi.pdf. Diakses pada tanggal 26 April 2016.

Kemenkes RI. (2017). Sebagian besar penderita hipertensi tidak menyadarinya. Retrieved fromhttp://www.depkes.go.id/article/vie w/17051800002/sebagian-besarpenderita-hipertensi-tidakmenyadarinya.html. Diakses pada tanggal 17 Mei 2017.

Maryam, R. S. (2008). Mengenal Usia Lanjut dan Perawatannya, Jakarta: Salemba.

Notoatmodjo, S. (2003). Pendidikan dan Perilaku Kesehatan, Jakarta: Rineka Cipta

Riskesdas. (2013). Badan penelitian dan pengembangan Kesehatan Kementerian RI tahun 2013. Retrieved from http://www.depkes.go.id/resources/down load/general/Hasil Riskesdas 2013.pdf. Diakses pada tanggal 19 Oktober 2014.

Sigalingging, G. (2011). Pengaruh sosial 
budaya dan sosial ekonomi keluarga lansia terhadap pemanfaatan posyandu lansia di Wilayah Kerja Puskesmas Darussalam Medan (Master's Thesis). Universitas Sumatera Utara.

Siringoringo, M., Hiswani, \& J. (2013). Faktor-Faktor yang berhubungan dengan kejadian hipertensi pada lansia di Desa Sigaol Simbolon Kabupaten Samosir Tahun 2013. Gizi, Kesehatan Reproduksi Dan Epidemiologi, 2(6).

Sugiharto, A. (2007). Faktor-faktor risiko hipertensi grade II pada masyarakat (studi kasus di kabupaten Karanganyar). Doctoral Dissertation, Program Pascasarjana Universitas Diponegoro.

Susriyanti, S. (2014). Hubungan dukungan keluarga dengan perilaku perawatan hipertensi pada lansia di Gamping Sleman Yogyakarta (Doctoral dissertation. 'Aisyiyah Yogyakarta.

Trianni, L. (2013). Hubungan Antara Tingkat Pendidikan Dan Dukungan Keluarga Terhadap Kepatuhan Berobat Pada Pasien Hipertensi Di Puskesmas Ngaliyan Semarang. Karya Ilmiah.

Tumenggung, I. (2013). Hubungan dukungan sosial keluarga dengan kepatuhan diet pasien hipertensi di RSUD Toto Kablia Kabupaten Bone Bolango. Politeknik Kesehatan Gorontalo, 7(01).

Wahyuni., dan Eksanoto, D. (2013). Hubungan tingkat pendidikan dan jenis kelamin dengan kejadian hipertensi di Kelurahan Jagalan di Wilayah Kerja Puskesmas Pucang Sawit Surakarta. Jurnal Ilmu Keperawatan Indonesia, 1(1), 79-85.

WHO. (2012). World Health Day 2013: Measure your blood pressure, reduce your risk. 